\title{
Transition Threshold of Granite Mechanical Characteristics at High Temperature
}

\author{
Hongjun Guo $\mathbb{D}^{1},{ }^{1}$ Ming Ji $\mathbb{D}^{2},{ }^{2}$ and Dapeng Liu ${ }^{1}$ \\ ${ }^{1}$ Jiangsu Vocational Institute of Architectural Technology, Xuzhou 221116, China \\ ${ }^{2}$ Key Laboratory of Deep Coal Resource Mining, Ministry of Education of China, School of Mines, \\ China University of Mining \& Technology, Xuzhou 221116, China \\ Correspondence should be addressed to Ming Ji; jiming@cumt.edu.cn
}

Received 16 June 2020; Accepted 18 July 2020; Published 17 August 2020

Academic Editor: Hailing Kong

Copyright (C) 2020 Hongjun Guo et al. This is an open access article distributed under the Creative Commons Attribution License, which permits unrestricted use, distribution, and reproduction in any medium, provided the original work is properly cited.

No unified criterion exists for the transition threshold of rock mechanical characteristics. We combine rock stress-strain curves to propose an increment ratio of axial pressure based on uniaxial compression tests on granite at high temperature. The behavior of the increment ratio of strain, elastic modulus, Poisson's ratio, and energy with axial pressure is analyzed, and the following conclusions are drawn. (1) High temperatures aggravate rock deterioration, reduce failure strength, and enhance ductility characteristics. (2) Under loading, the compression-to-elasticity and elasticity-to-plasticity transition thresholds for rock occur, respectively, at $20 \%-35 \%$ and $75 \%-80 \%$ stress levels at temperatures of $25-800^{\circ} \mathrm{C}$. (3) The source data for calculating rock deformation parameters or unloading points for unloading tests can be selected over the stress level range of $35 \%-75 \%$.

\section{Introduction}

Rock mechanics tests have gathered significant attention worldwide. The tests include uniaxial and triaxial, singlestress and complex-stress paths, dry and saturated environments, freeze-thaw and high-temperature conditions, cracks and pore pressure, and natural and prefabricated samples, as well as auxiliary methods (e.g., acoustic emission, electromagnetic or infrared radiation, and computed tomography scanning) and have provided important results [1-6].

However, some qualitative conclusions are difficult to quantify from the available results as described by the following examples. (1) In the stress-strain curve, the transition zone or conversion threshold in the compaction-to-elastic and elastic-to-plastic stages is not quantified and the selection is inevitably affected by subjective factors. (2) When the stress-strain curve is used to solve for deformation parameters (elastic modulus and Poisson's ratio), the data interval selection varies from user to user and is often chosen on the premise of conforming to objective facts. (3) There is no uniform standard for selecting the unloading point in an uniaxial or triaxial unloading test. Most previous studies have chosen $80 \%$ of the peak rock strength as the unloading point (Table 1). This introduces confusion in the calculation of relevant parameters or design of complex test schemes.

In view of the abovementioned problems, Ji [19] combined conventional triaxial compression tests to explore the critical value of rock damage transitions under triaxial compression [20]. Following on this work, we further study the mechanical properties of rock after high temperature under different stress conditions.

\section{Materials and Methods}

The granite samples used in the tests were collected from a mine in Weifang, Shandong, China, with an average density of $2.612 \mathrm{~g} / \mathrm{cm}^{3}$ at room temperature. The samples were processed into standard cylindrical specimens of $\Phi 50 \mathrm{~mm} \times H 100 \mathrm{~mm}$ (error $\pm 0.5 \mathrm{~mm}$ ) following the International Society of Rock Mechanics (ISRM) standards, as shown in Figure 1. The tests were performed using an MTS815.02 electrohydraulic servo material test system (Figure 2). 
TABLE 1: Statistics of unloading level in rock unloading test.

\begin{tabular}{lcc}
\hline Lithology & Unloading level (\%) & Researchers \\
\hline Rock masses with interlayer staggered zones & $25,40,50,60,70,80$ & Duan et al. [7] \\
Tuffaceous sandstone & $65-75$ & Zhou et al. [8] \\
Granite & $70-80$ & Duan et al. [9] \\
Sandstone & $85-95$ & Liu et al. [10] \\
Sandstone & $70,80,90$ & Liu et al. [11] \\
Rhyolite & $80-90$ & Zhong et al. [12] \\
Rock mass inside the composite slope & 80 & Chang et al. [13] \\
Granite, red sandstone & 80 & Du et al. [14] \\
Sandstone & 80 & Yang et al. [15] \\
Granite & 80 & Qin et al. [16] \\
Marble & 80 & Dai et al. [17] \\
\hline
\end{tabular}

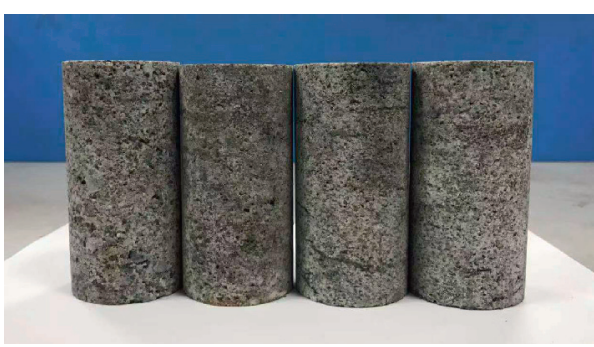

FIGURE 1: Granite specimen.

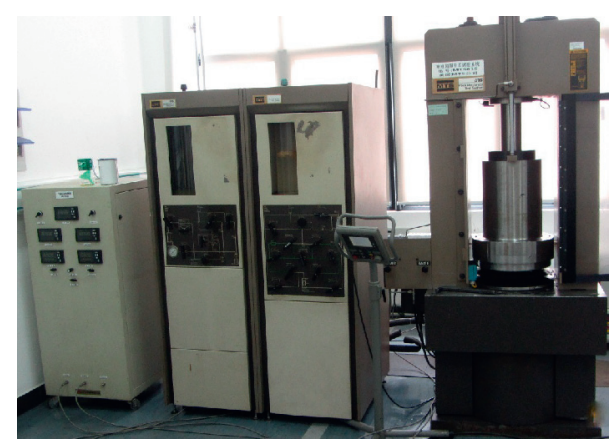

FIgURE 2: MTS815.02 testing system.

(1) The specimen was subjected to high-temperature treatment at $25,200,400,600$, and $800^{\circ} \mathrm{C}$. To ensure uniform internal heating, the temperature was raised to the set value and held constant for $2 \mathrm{~h}$ and then cooled to room temperature.

(2) Axial pressure was applied using the displacement control mode at a loading rate of $0.003 \mathrm{~mm} / \mathrm{s}$ until the specimen broke.

\section{Results}

The uniaxial compression test data of granite at high temperature are given in Table 2, and the typical data were selected to draw the stress-strain curve as shown in Figure 3.

The compression process goes through several stages including compaction, elasticity, yield, failure, and residue.
TABle 2: Test data.

\begin{tabular}{lccc}
\hline$T\left({ }^{\circ} \mathrm{C}\right)$ & No. & $\varepsilon_{1} \times 10^{-3}$ & $\sigma_{1 \max }(\mathrm{MPa})$ \\
\hline \multirow{3}{*}{25} & $\# 1$ & 4.16 & 120.37 \\
& $\# 2$ & 4.04 & 116.61 \\
& $\# 3$ & 4.26 & 122.28 \\
200 & $\# 1$ & 4.83 & 121.77 \\
& $\# 2$ & 4.72 & 117.77 \\
& $\# 3$ & 4.88 & 120.21 \\
400 & $\# 1$ & 4.23 & 97.94 \\
& $\# 2$ & 4.44 & 95.56 \\
600 & $\# 3$ & 4.32 & 98.82 \\
& $\# 1$ & 5.86 & 54.62 \\
& $\# 2$ & 5.72 & 53.69 \\
800 & $\# 3$ & 5.75 & 58.95 \\
& $\# 1$ & 5.45 & 41.91 \\
& $\# 2$ & 5.15 & 41.15 \\
& $\# 3$ & 5.33 & 43.80 \\
\hline
\end{tabular}

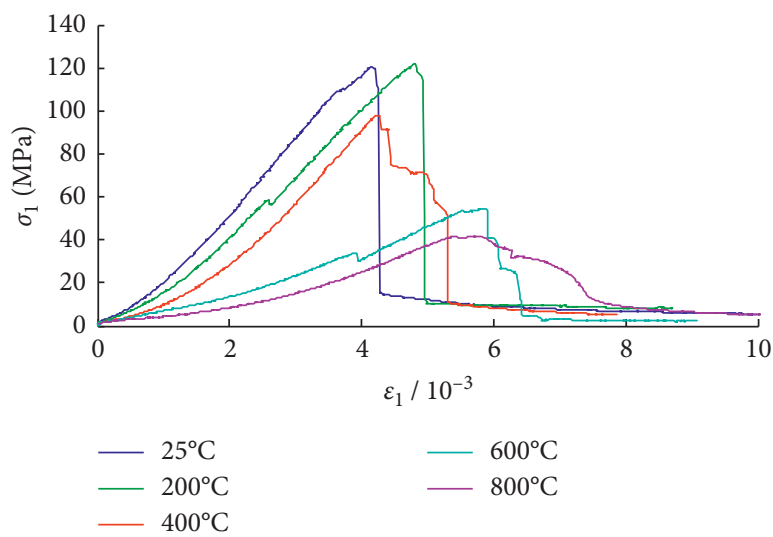

Figure 3: Stress-strain curves.

With increasing temperature, the strain growth rate is more prominent than the stress growth rate and ductility characteristics are observed. Rock strength is less affected when the temperature is $<200^{\circ} \mathrm{C}$. Above $200^{\circ} \mathrm{C}$, rock strength reduces approximately linearly. Between 400 and $600^{\circ} \mathrm{C}$, the strength drop is more significant [21, 22], as shown in Figure 4. 


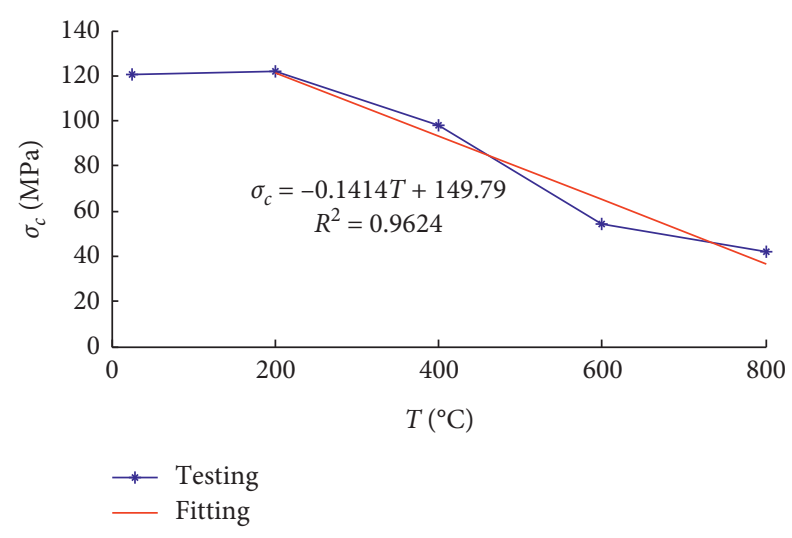

FIGURE 4: Failure strength-temperature curve.

3.1. Strain Evolution. Under uniaxial compression, rock strain is only related to axial pressure. To study the effect of stress level, we introduce the concept of increment ratio of strain to axial pressure [19, 23-25], namely, the ratio of the increase in strain to the increase in axial pressure, which is expressed as follows:

$$
\frac{\Delta \varepsilon_{1(t+1)}}{\Delta \sigma_{1(t+1)}}=\frac{\varepsilon_{1(t+1)}-\varepsilon_{1(t)}}{\sigma_{1(t+1)}-\sigma_{1(t)}},
$$

where $\Delta \varepsilon_{1(t+1)}$ is the increment of axial strain at $t+1 ; \varepsilon_{1(t+1)}$ and $\varepsilon_{1(t)}$ are the axial strains at $t+1$ and $t$; $\Delta \sigma_{1(t+1)}$ is the increment of axial pressure at $t+1$; and $\sigma_{1(t+1)}$ and $\sigma_{1(t)}$ are the axial pressures at $t+1$ and $t$.

The increment ratio of strain to axial pressure is a physical quantity that characterizes the rapid or slow change of strain with axial pressure. It well reflects the influence of axial pressure changes on rock deformation and damage during loading, as well as the internal structural response to the change of external macromechanical state. Larger increment ratios of strain to axial pressure are associated with higher sensitivity of rock deformation to changes of axial pressure. The relationship between the increment ratio of strain to axial pressure and stress level is obtained by combining the test data and equation (1), as shown in Figure 5.

The increment ratio of strain to axial pressure shows a peak at the approximate compression-to-elastic and elasticto-plastic transition stages in the stress-strain curve. This indicates that the ratio can be used as an indicator for assessing a change of rock mechanical characteristics. The corresponding stress levels of axial pressure are listed in Table 3 .

It should be emphasized that (1) the rock samples are heterogeneous and anisotropic, and the transition points of their mechanical characteristics should be over a small stress range; (2) some specimens also show a strong response in the increment ratio of strain to axial pressure during the compaction stage, which is related to the initial state of their internal pores and fractures.

The compaction-to-elastic transition point in the stressstrain curve changes with increasing temperature, which is related to the internal cracks [21], whereas the elastic-toplastic transition point remains essentially unchanged at about $80 \%$ stress level.

3.2. Deformation Parameter Evolution. The elastic modulus and Poisson's ratio are important mechanical parameters of rock, and their changes are closely related to deformation and damage. Similarly, the increment ratio of deformation parameters to axial pressure can also be obtained:

$$
\left\{\begin{array}{c}
\frac{\Delta E_{t+1}}{\Delta \sigma_{1(t+1)}}=\frac{E_{t+1}-E_{t}}{\sigma_{1(t+1)}-\sigma_{1(t)}} \\
\frac{\Delta \mu_{t+1}}{\Delta \sigma_{1(t+1)}}=\frac{\mu_{t+1}-\mu_{t}}{\sigma_{1(t+1)}-\sigma_{1(t)}}
\end{array},\right.
$$

where $\Delta E_{t+1}$ is the increment of elastic modulus at $t+1 ; E_{t+1}$ and $E_{t}$ are the elastic modulus at $t+1$ and $t ; \Delta \mu_{t+1}$ is the increment of Poisson's ratio at $t+1$; and $\mu_{t+1}$ and $\mu_{t}$ are the Poisson ratios at $t+1$ and $t$.

The relationship between deformation parameters and the increment ratio to axial pressure and stress level is shown in Figures 6 and 7.

The results shown in Figures 6 and 7 are consistent with those in Figure 5, further indicating that a significant change of the increment ratio of rock parameters to axial compression can be used as an indicator of its mechanical characteristics. Table 4 lists the stress levels under different temperature conditions.

3.3. Strain Energy Evolution. To further verify the accuracy of the results, we analyzed changes of rock strain energy. The law of energy conservation states that energy transformation occurs during rock deformation and failure. The change of thermal energy is not considered because the specimens were cooled to room temperature after heat treatment and loading was also performed at room temperature. Therefore, according to the law of thermodynamics, energy production mainly comes from the work of external forces. During uniaxial compression, the external forces on the rock specimen are only the axial pressure of the testing machine. The total energy absorbed by the rock sample is therefore the axial strain energy $[18,26]$, then

$$
U_{1}=\int_{0}^{\varepsilon_{1(t)}} \sigma_{1} d \varepsilon_{1}
$$

where $\varepsilon_{1(t)}$ is the axial strain at any $t$.

According to the concept of definite integral in equation (3), we adopt the method of microelement area, which is

$$
U_{1}=\sum_{t=0}^{t_{0}} \frac{1}{2}\left(\sigma_{1(t+1)}+\sigma_{1(t)}\right)\left(\varepsilon_{1(t+1)}-\varepsilon_{1(t)}\right) .
$$

In combination with the previously described concept, the increment ratio of strain energy to axial pressure can be expressed as follows: 


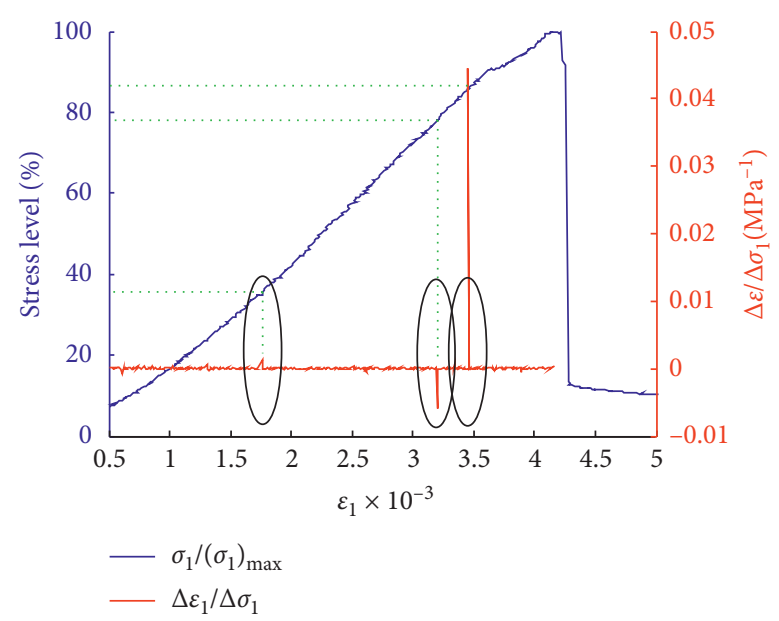

(a)

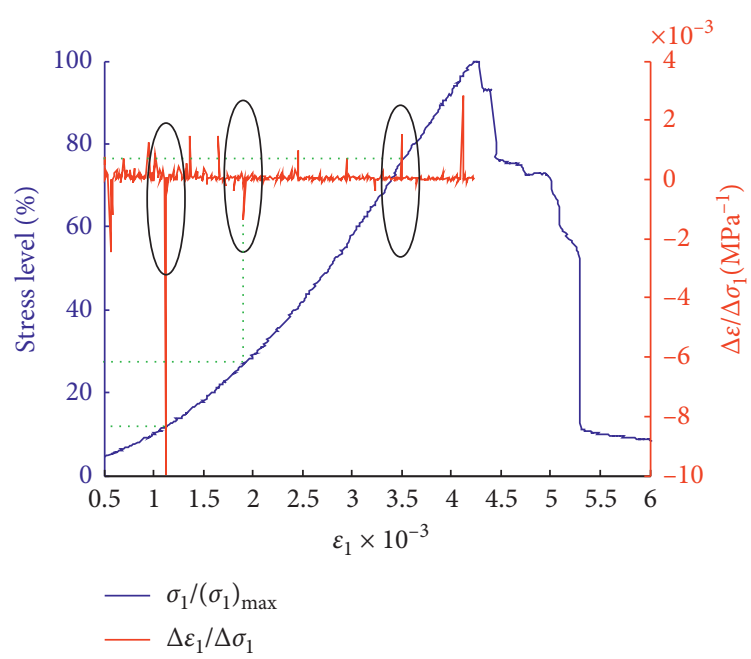

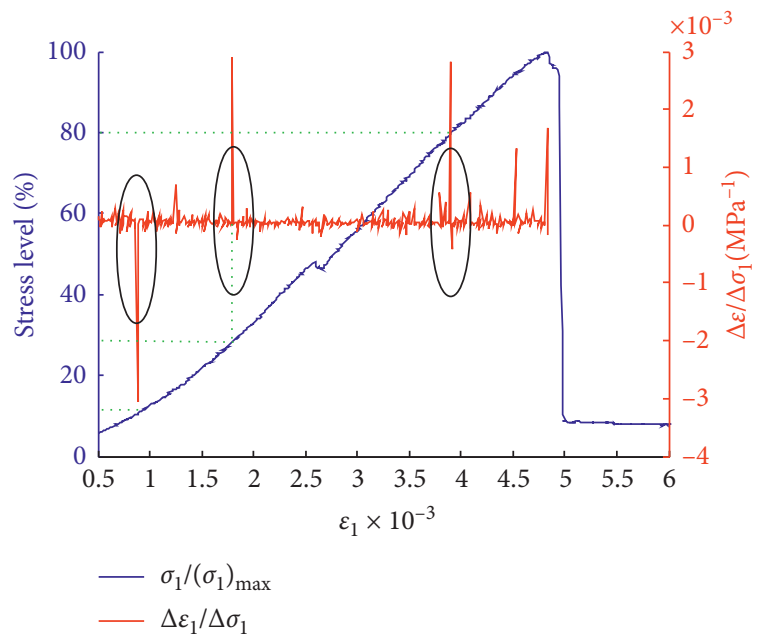

(b)

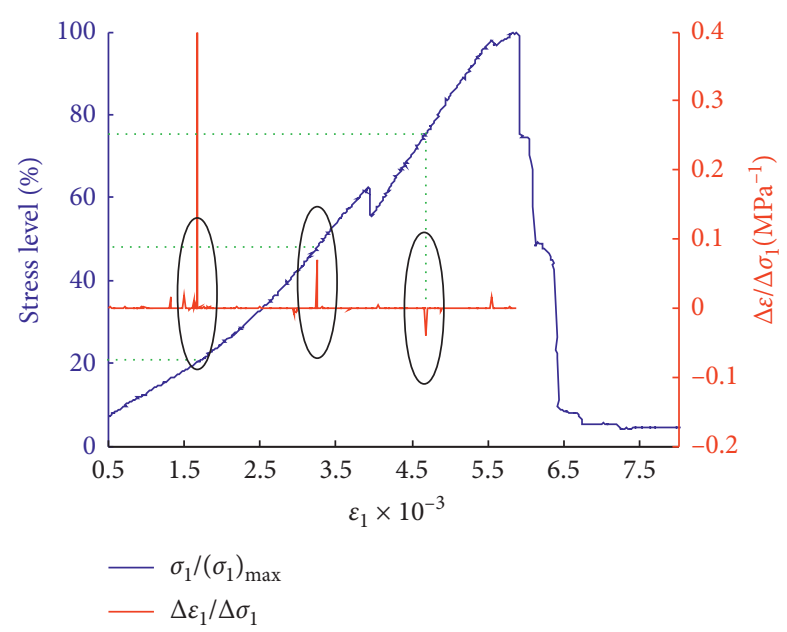

(d)

(c)

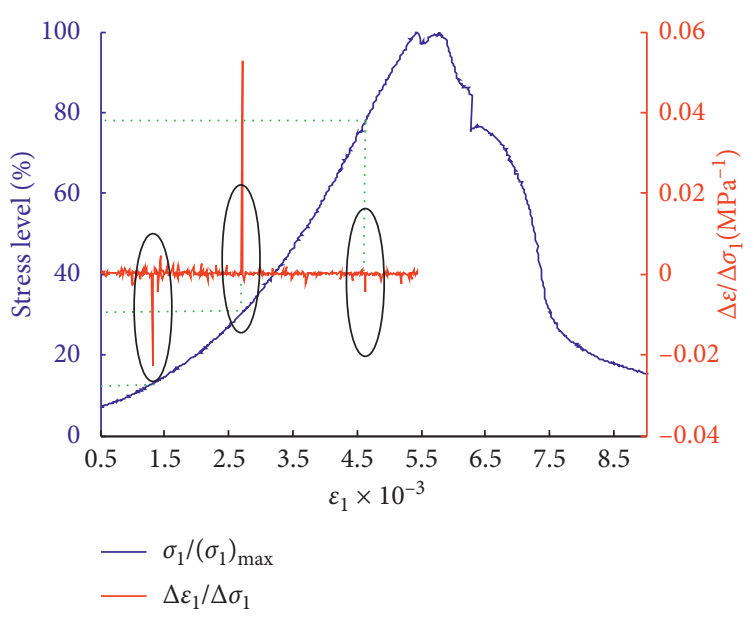

(e)

FIgURe 5: Evolution curve of the increment ratio of strain to axial pressure. (a) $25^{\circ} \mathrm{C}$, (b) $200^{\circ} \mathrm{C}$, (c) $400^{\circ} \mathrm{C}$, (d) $600^{\circ} \mathrm{C}$, and (e) $800^{\circ} \mathrm{C}$.

$$
\frac{\Delta U_{t+1}}{\Delta \sigma_{1(t+1)}}=\frac{U_{t+1}-U_{t}}{\sigma_{1(t+1)}-\sigma_{1(t)}},
$$

where $\Delta U_{t+1}$ is the increment of strain energy at $t+1$, and $U_{t+1}$ and $U_{t}$ are the strain energies at $t+1$ and $t$. 
TABLE 3: Statistics of the incremental ratio of strain to axial pressure peak.

\begin{tabular}{lcc}
\hline$T\left({ }^{\circ} \mathrm{C}\right)$ & & Stress level $(\%)$ \\
& Compaction to elastic & Elastic to plastic \\
\hline 25 & 35.75 & $78.17-86.13$ \\
200 & $11.55-28.49$ & 79.65 \\
400 & $12.34-26.97$ & 76.13 \\
600 & 20.98 & 74.98 \\
800 & $13.23-31.02$ & 78.1 \\
\hline
\end{tabular}

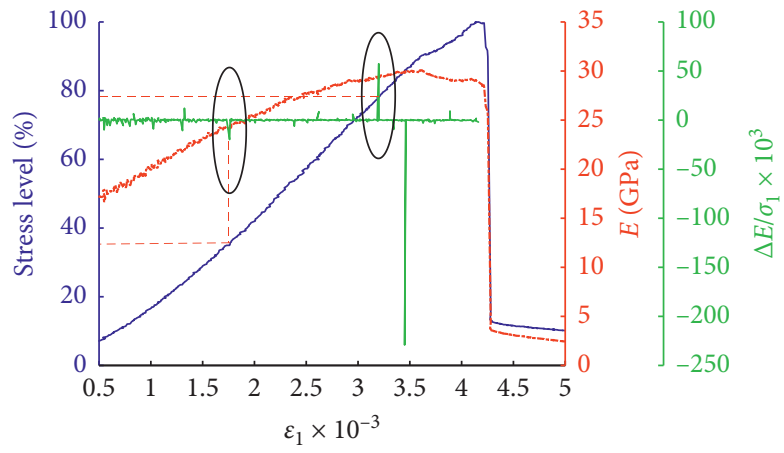

$$
\begin{aligned}
- & \Delta E / \mathrm{C} \sigma_{1} \\
- & \sigma_{1} /\left(\sigma_{1}\right) \max \\
. .- & E
\end{aligned}
$$

(a)

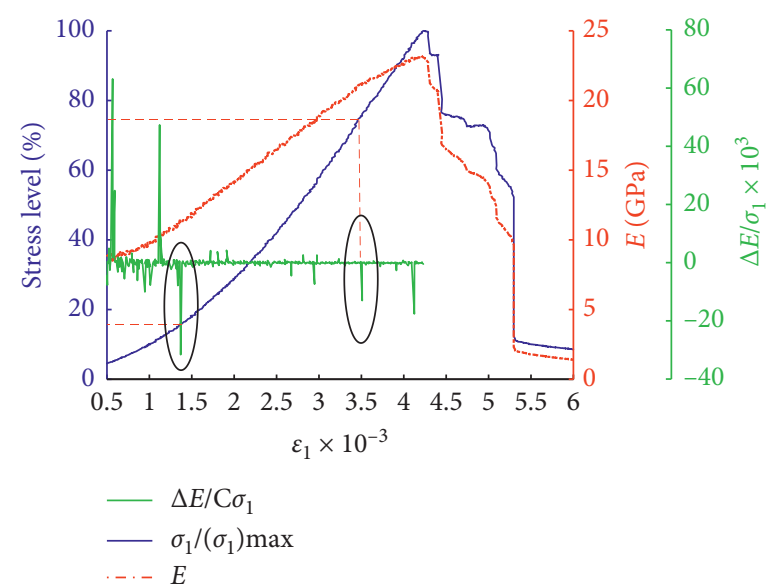

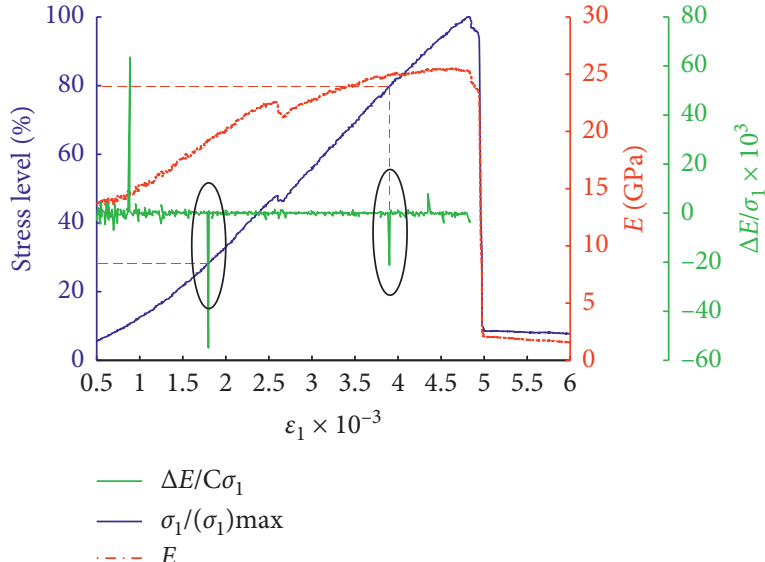

(b)

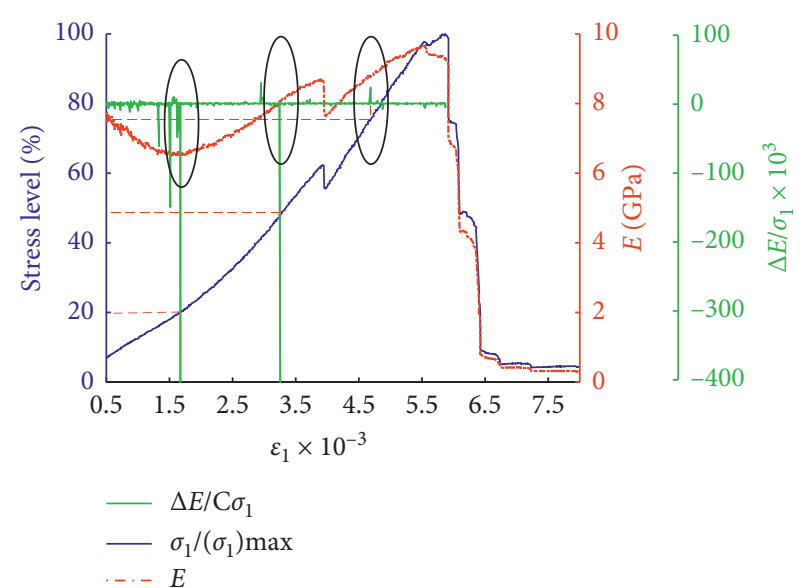

(d)

(c)

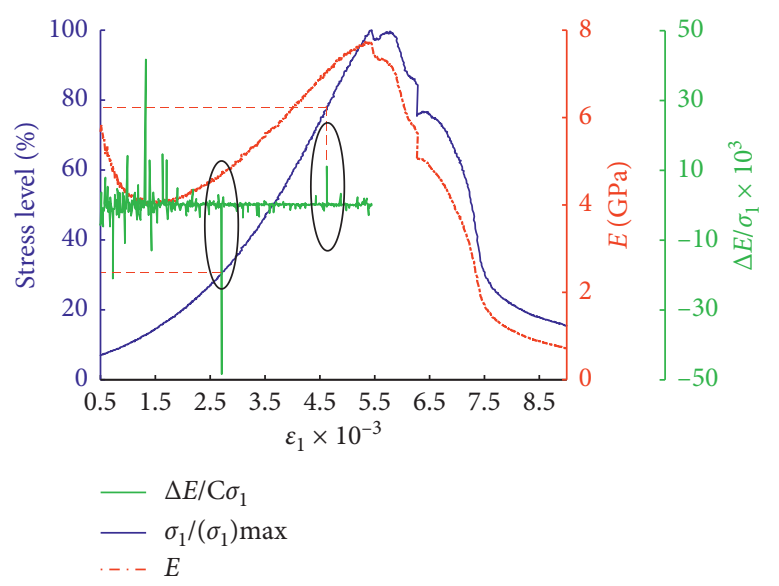

(e)

Figure 6: Evolution curve of the increment ratio of elastic modulus to axial pressure. (a) $25^{\circ} \mathrm{C}$, (b) $200^{\circ} \mathrm{C}$, (c) $400^{\circ} \mathrm{C}$, (d) $600^{\circ} \mathrm{C}$, and (e) $800^{\circ} \mathrm{C}$. 


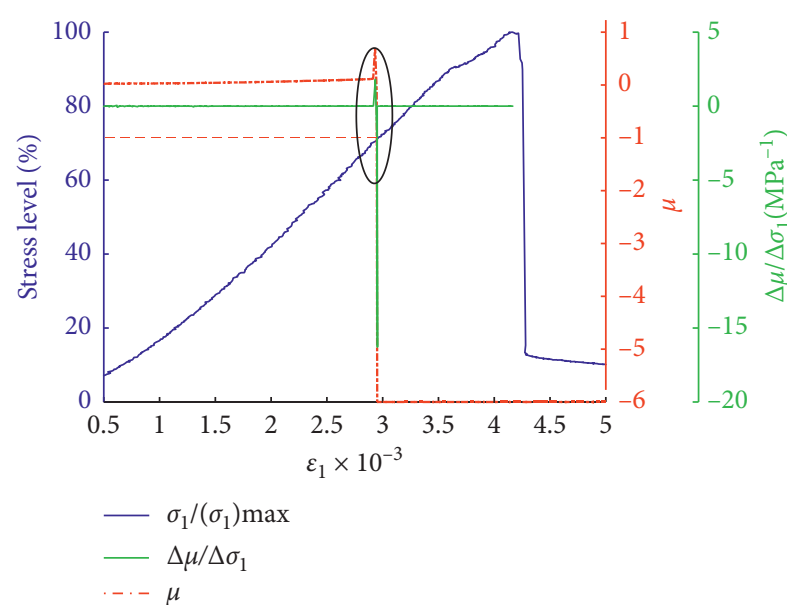

(a)

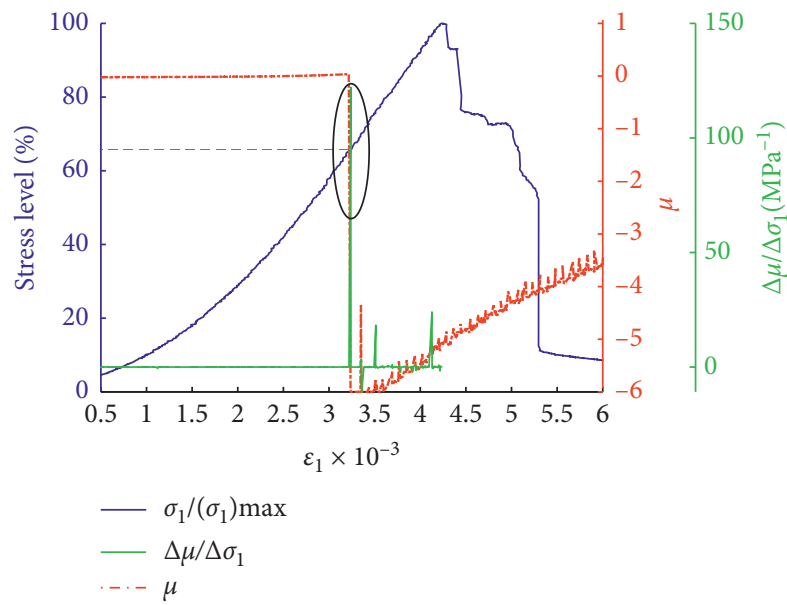

(c)

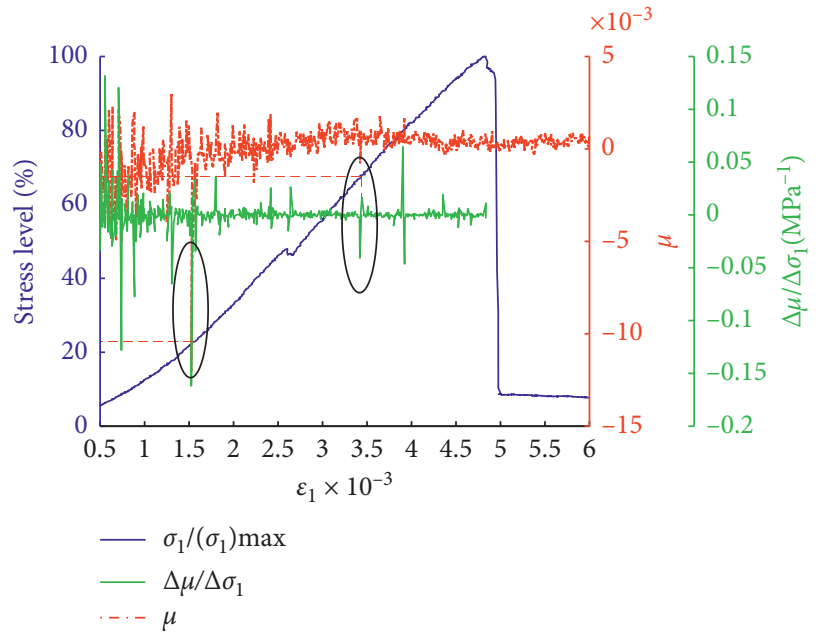

(b)

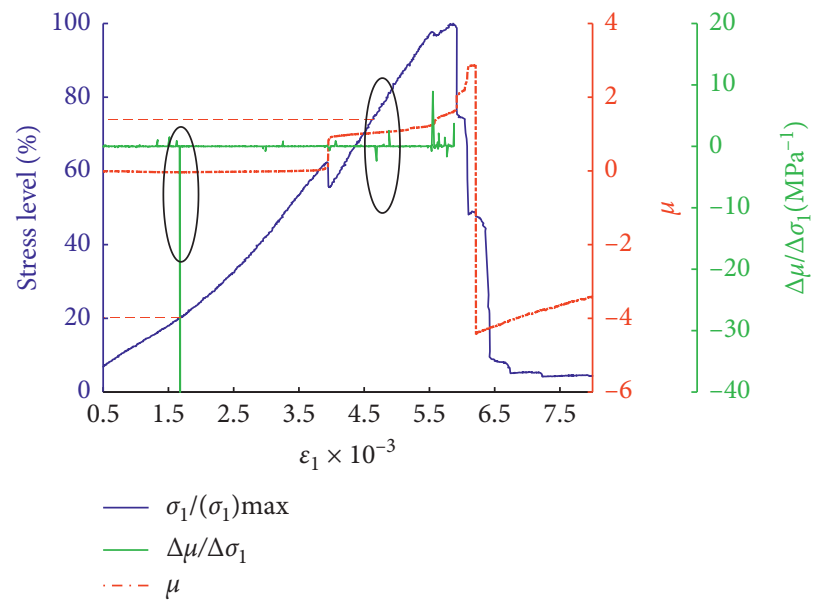

(d)

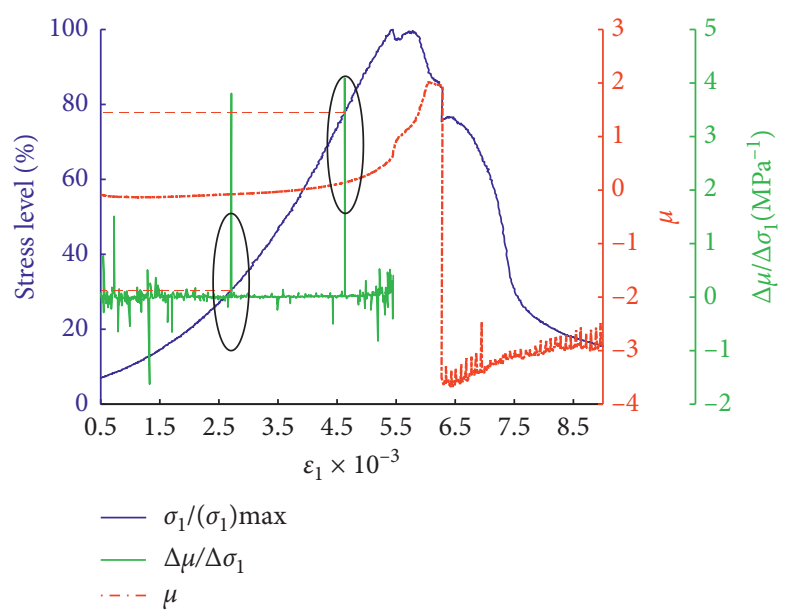

(e)

Figure 7: Evolution curve of the increment ratio of Poisson's ratio to axial pressure. (a) $25^{\circ} \mathrm{C}$, (b) $200^{\circ} \mathrm{C}$, (c) $400^{\circ} \mathrm{C}$, (d) $600^{\circ} \mathrm{C}$, and (e) $800^{\circ} \mathrm{C}$.

Figure 8 shows the relationship between strain energy and increment ratio of strain energy to axial pressure and stress level during loading.

The threshold of rock mechanical characteristics is consistent with the conclusions obtained from strain, elastic modulus, and Poisson's ratio. The corresponding stress levels of axial pressure are listed in Table 5.

Critical points are believed to exist at the compaction-to-elasticity and elasticity-to-plasticity transitions during rock loading. A peak in the increment ratio of 
TABLE 4: Statistics of the incremental ratio of deformation parameters to axial pressure peak.

\begin{tabular}{|c|c|c|c|c|}
\hline \multirow{2}{*}{$T\left({ }^{\circ} \mathrm{C}\right)$} & \multicolumn{4}{|c|}{ Stress level (\%) } \\
\hline & $(\text { Compaction to elastic })^{E}$ & $(\text { Elastic to plastic })^{E}$ & (Compaction to elastic) $^{\mu}$ & 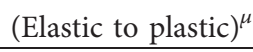 \\
\hline 25 & 35.75 & 78.17 & & 71.68 \\
\hline 200 & 28.49 & 79.65 & 23.24 & 67.36 \\
\hline 400 & 15.96 & 74.4 & & 65.83 \\
\hline 600 & 19.9 & 75.18 & 20.12 & 74.56 \\
\hline 800 & 31.02 & 77.86 & 30.31 & 77.86 \\
\hline
\end{tabular}
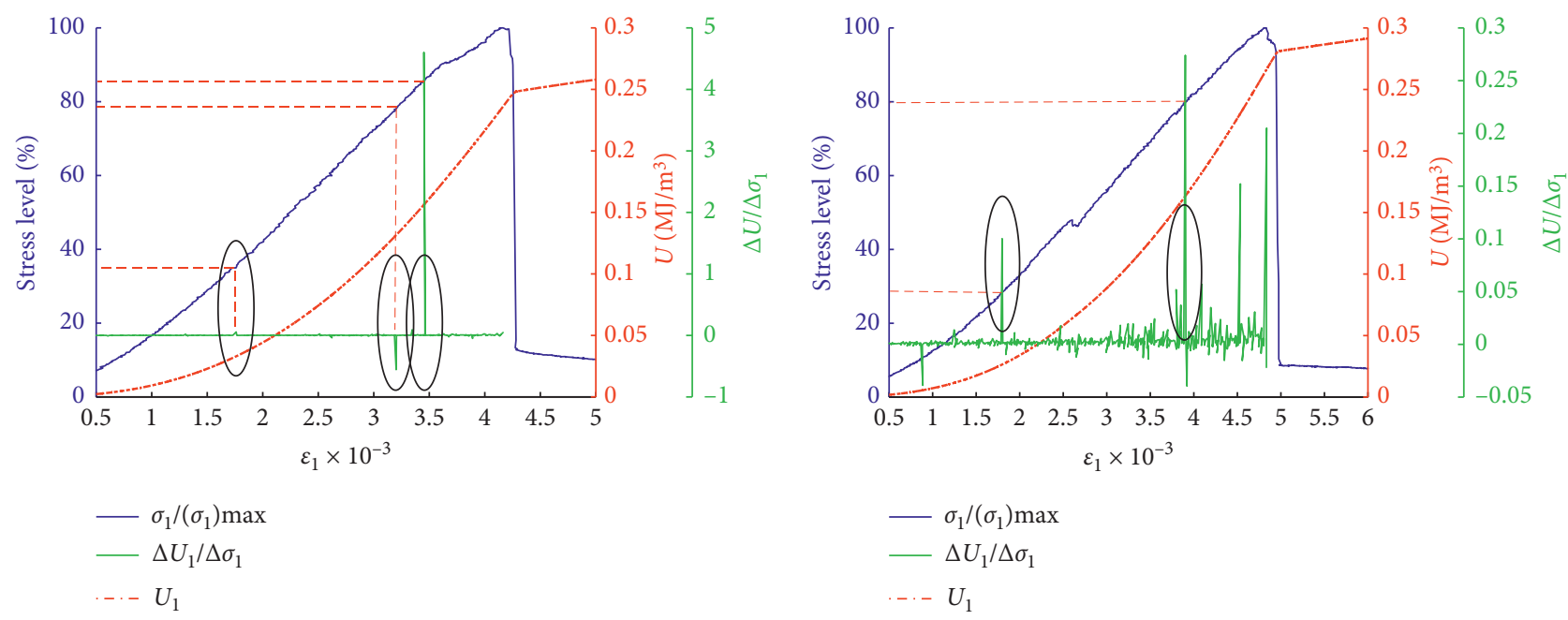

(a)

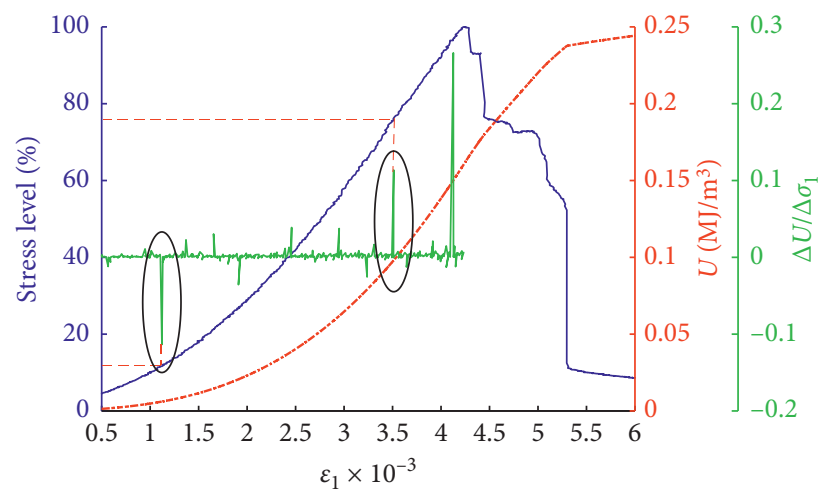

(b)

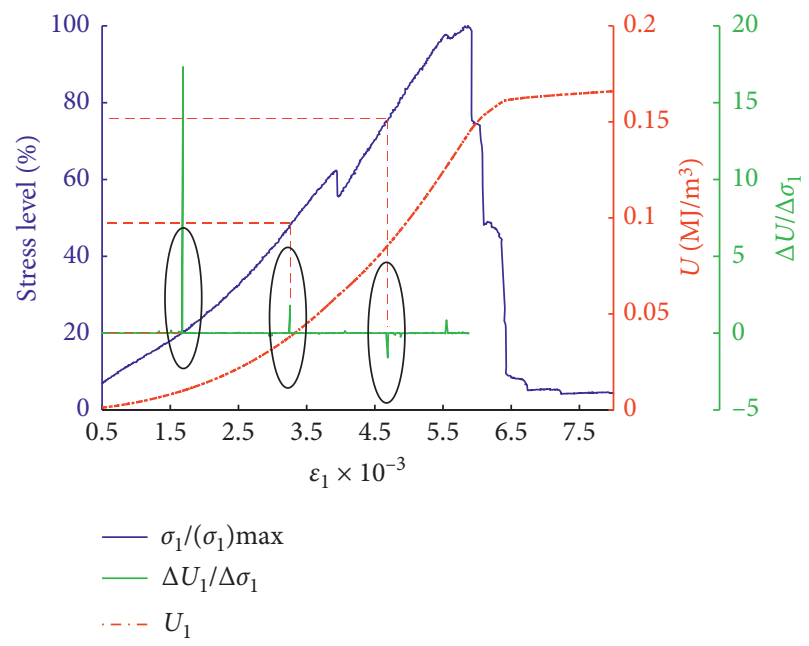

(d)

Figure 8: Continued. 


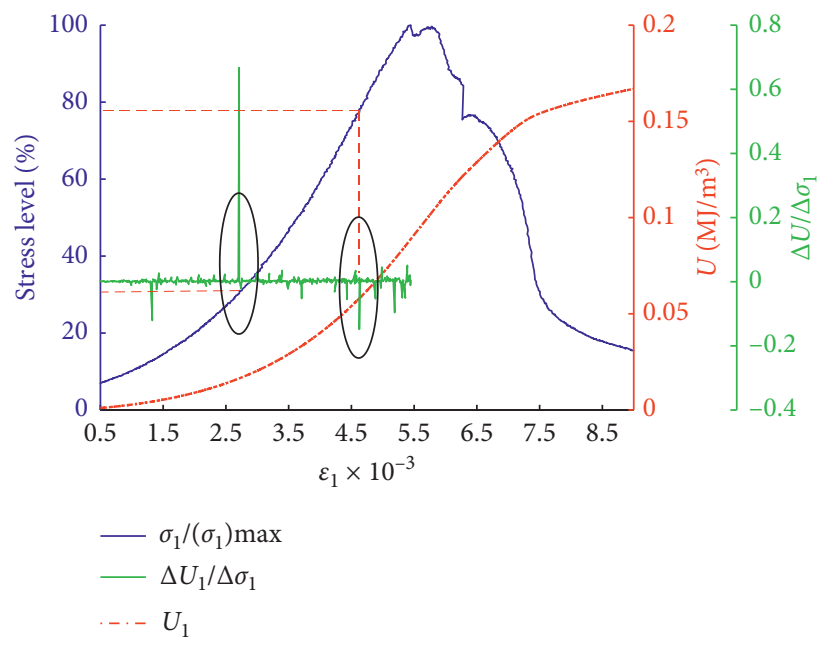

(e)

Figure 8: Evolution curve of the increment ratio of strain energy to axial pressure. (a) $25^{\circ} \mathrm{C}$, (b) $200^{\circ} \mathrm{C}$, (c) $400^{\circ} \mathrm{C}$, (d) $600^{\circ} \mathrm{C}$, and (e) $800^{\circ} \mathrm{C}$.

TABLE 5: Statistics of the incremental ratio of strain energy to axial pressure peak.

\begin{tabular}{lcr}
\hline$T\left({ }^{\circ} \mathrm{C}\right)$ & & Stress level (\%) \\
& Compaction to elastic & Compaction to elastic \\
\hline 25 & 34.97 & $78.49-85.85$ \\
200 & 28.49 & 80.07 \\
400 & 12.34 & 75.56 \\
600 & 20.12 & 75.6 \\
800 & 31.02 & 77.86 \\
\hline
\end{tabular}

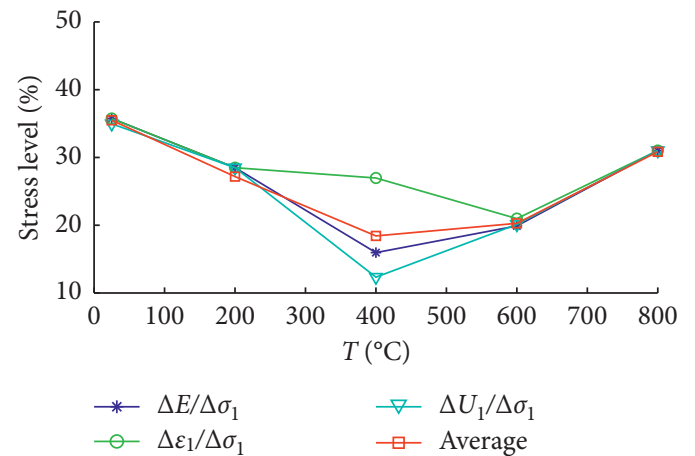

(a)

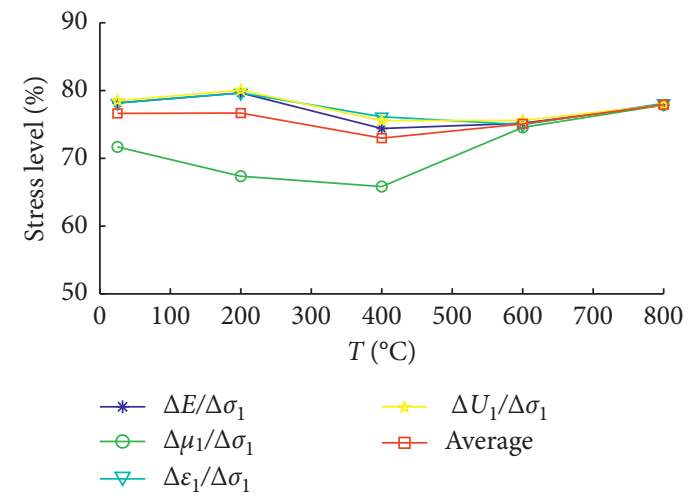

(b)

FIgURE 9: Relationship between the transition threshold of the rock mechanical characteristics and temperature. (a) Compression-toelasticity transition. (b) Elasticity-to-plasticity transition.

different parameters to axial pressure can be used as the basis for evaluating the stress level.

\section{Discussion}

Figure 9 shows the loads corresponding to the critical compaction-to-elasticity and elasticity-to-plasticity transition points of granite under compression and variable temperature. The transition thresholds of rock mechanical characteristics obtained from the increment ratio of different parameters to axial pressure are in good agreement. The difference of initial rock state is enlarged to some extent at high temperature. The threshold of the compression-to-elasticity transition is therefore strongly affected by temperature. The transition threshold 


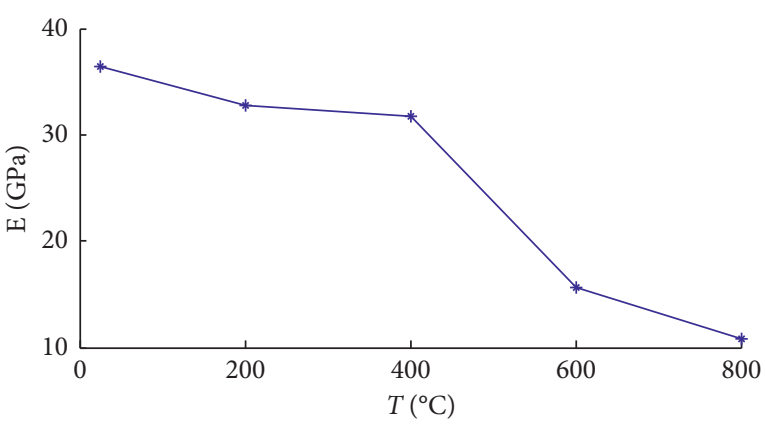

FIgURE 10: Relationship between elastic modulus and temperature.

generally occurs at the $20 \%-35 \%$ stress level. The rock enters the elastic stage under low-stress conditions at $400-600^{\circ} \mathrm{C}$. However, the relationship between the elasticity-to-plasticity transition threshold and temperature is strong and remains at $75 \%-80 \%$ stress level over the full investigated temperature range $\left(25-800^{\circ} \mathrm{C}\right)$.

Based on the above conclusions, the elastic modulus of granite under different temperatures was analyzed using data from the $40 \%-70 \%$ stress level range. The results are shown in Figure 10. The elastic modulus decreases irregularly with increasing temperature, which is consistent with the behavior of failure strength.

Because rock deformation in the elastic stage is reversible and does not cause substantial damage to itself, it is suggested that the unloading point be lower than the elasticityto-plasticity transition threshold in unloading tests with complex-stress paths to avoid damage caused by higher loads later in the test.

\section{Conclusions}

We combine high-temperature uniaxial compression tests on granite with the concept of an increment ratio of axial pressure. The following conclusions are drawn:

(1) With increasing temperature, granite transitions from brittle to ductile failure. When the temperature exceeds $200^{\circ} \mathrm{C}$, its strength decreases approximately linearly.

(2) Based on the analysis of the increment ratio of granite parameters (strain, deformation parameters, and strain energy) to axial pressure, it is considered that the transition thresholds of compaction to elasticity and elasticity to plasticity are $20 \%-35 \%$ and $75 \%-80 \%$ stress level, respectively.

(3) In general, rock deformation parameters can be calculated over the stress level range of $35 \%-75 \%$. In unloading tests, we suggest that the unloading point is lower than the elasticity-to-plasticity transition threshold.

\section{Data Availability}

The data used to support the findings of the study are available from the corresponding author upon request.

\section{Conflicts of Interest}

The authors declare that there are no conflicts of interest regarding the publication of this paper.

\section{Acknowledgments}

This study was supported by Jiangsu Construction System Science and Technology Project (Guidance) (2019ZD080), Xuzhou Science and Technology Plan Project (KC17156), the Fundamental Research Funds for the Central Universities (2017XKQY044 and 2017XKQY045), and University Scientific Research Project (Doctoral Program) (JYJBZX1908). The authors thank Esther Posner, PhD, from Liwen Bianji, Edanz Editing China (http://www.liwenbianji.cn/ac), for editing the English text of a draft of this manuscript.

\section{References}

[1] A. Momeni, M. Karakus, G. R. Khanlari, and M. Heidari, "Effects of cyclic loading on the mechanical properties of a granite," International Journal of Rock Mechanics and Mining Sciences, vol. 77, pp. 89-96, 2015.

[2] A. Singh, C. Kumar, L. G. Kannan, K. S. Rao, and R. Ayothiraman, "Estimation of creep parameters of rock salt from uniaxial compression tests," International Journal of Rock Mechanics and Mining Sciences, vol. 107, pp. 243-248, 2018.

[3] H. Munoz, A. Taheri, and E. K. Chanda, "Fracture energybased brittleness index development and brittleness quantification by pre-peak strength parameters in rock uniaxial compression," Rock Mechanics and Rock Engineering, vol. 49, no. 12, pp. 4587-4606, 2016.

[4] H. Guo, M. Ji, Y. Zhang, and M. Zhang, "Study of mechanical property of rock under uniaxial cyclic loading and unloading," Advances in Civil Engineering, vol. 2018, Article ID 1670180, 6 pages, 2018

[5] M. Ji, Y. D. Zhang, W. P. Liu, and L. Cheng, "Damane evolution law based on acoustic emission and weibull distribution of granite under uniaxial stress," Acta Geodynamica Et Geomaterialia, vol. 11, no. 3, pp. 269-277, 2014.

[6] M. Ji, K. Chen, and H. J. Guo, "Constitutive model of rock uniaxial damage based on rock strength Statistics," Advances in Civil Engineering, vol. 2018, Article ID 5047834, 8 pages, 2018.

[7] S. D. Duan, Q. Jiang, D. P. Xu, and G. F. Liu, "Experimental study of mechanical behavior of interlayer staggered zone under cyclic loading and unloading condition," International Journal of Geomechanics, vol. 20, no. 3, pp. 1-12, 2020.

[8] Z. Zhou, H. Zhan, J. Hu, and C. Ren, "Characteristics of unloading creep of tuffaceous sandstone in east tianshan tunnel under freeze-thaw cycles," Advances in Materials Science and Engineering, vol. 2019, Article ID 7547564, 16 pages, 2019.

[9] K. Duan, Y. Ji, W. Wu, and C. Y. Kwok, "Unloading-induced failure of brittle rock and implications for excavation-induced strain burst," Tunnelling and Underground Space Technology, vol. 84, pp. 495-506, 2019.

[10] J. Liu and J. P. Li, "Experimental Research on sandstone prepeak unloading process under high confining pressure," Chinese Journal of Rock Mechanics and Engineering, vol. 30, no. 3, pp. 473-479, 2011. 
[11] X. R. Liu, J. Liu, D. L. Li, J. B. Wang, Z. J. Wang, and Z. L. Zhong, "Unloading mechanical properties and constitutive model of sandstone under different pore pressures and initial unloading levels," Journal of China Coal Society, vol. 42, no. 10, pp. 2592-2600, 2017.

[12] Z. B. Zhong, Experimental Study on Mechanical Properties of Microfissured Rhyolite Under Triaxial Test, Southwest Jiaotong University, Chengdu, China, 2013.

[13] Z. Chang, Q. Cai, W. Zhou, I. M. Jiskani, and R. Wang, "Effects of the loading and unloading conditions on crack propagation in high composite slope of deep open-pit mine," Advances in Civil Engineering, vol. 2019, Article ID 3168481, 11 pages, 2019.

[14] K. Du, M. Tao, X.-b. Li, and J. Zhou, "Experimental study of slabbing and rockburst induced by true-triaxial unloading and local dynamic disturbance," Rock Mechanics and Rock Engineering, vol. 49, no. 9, pp. 3437-3453, 2016.

[15] R. Yang, D. Ma, and Y. Yang, "Experimental investigation of energy evolution in sandstone failure during triaxial unloading confining pressure tests," Advances in Civil Engineering, vol. 2019, Article ID 37419752, 11 pages, 2019.

[16] T. Qin, H. Sun, H. Liu et al., "Experimental study on mechanical and acoustic emission characteristics of rock samples under different stress paths," Shock and Vibration, vol. 2018, Article ID 4813724, 9 pages, 2018.

[17] B. Dai, G. Zhao, L. Dong, and C. Yang, "Mechanical characteristics for rocks under different paths and unloading rates under confining pressures," Shock and Vibration, vol. 2015, Article ID 578748, 8 pages, 2015.

[18] G.-Y. Zhao, B. Dai, L.-J. Dong, and C. Yang, "Energy conversion of rocks in process of unloading confining pressure under different unloading paths," Transactions of Nonferrous Metals Society of China, vol. 25, no. 5, pp. 1626-1632, 2015.

[19] M. Ji and H. Guo, "Elastic-plastic threshold and rational unloading level of rocks," Applied Sciences, vol. 9, no. 15, p. 3164, 2019.

[20] Q. Sun, M. Ji, L. Xue, and T. M. Su, “The influence of moisture content on the acoustic emission at threshold of rock destruction," Acta Geodynamica et Geomaterialia, vol. 12, no. 3, pp. 279-287, 2015.

[21] X. L. Xu, F. Gao, and Z. Z. Zhang, "Research on triaxial compression test of granite after high temperatures," Rock and Soil Mechanics, vol. 35, no. 11, pp. 3177-3183, 2014.

[22] X. L. Xu, F. Gao, and Z. Z. Zhang, "Influence of confining pressure on deformation and strength properties of granite after high temperatures," Chinese Journal of Geotechnical Engineering, vol. 36, no. 12, pp. 2246-2252, 2014.

[23] T. Li, Siltstone's Mechanical Properties in Different Stress Paths and Research of Unloading Constitutive Model, China University of Mining and Technology, Xuzhou, China, 2015.

[24] D.-M. Zhang, Y.-S. Yang, Y.-P. Chu, X. Zhang, and Y.-G. Xue, "Influence of loading and unloading velocity of confining pressure on strength and permeability characteristics of crystalline sandstone," Results in Physics, vol. 9, pp. 13631370, 2018.

[25] S. L. Qiu, X. T. Feng, C. Q. Zhang, H. Zhou, and F. Sun, "Experimental research on mechanical properties of deepburied marble under different unloading rates of confining pressures," Chinese Journal of Rock Mechanics and Engineering, vol. 31, no. 8, pp. 1686-1698, 2012.

[26] D. Huang and Y. Li, "Conversion of strain energy in triaxial unloading tests on marble," International Journal of Rock Mechanics and Mining Sciences, vol. 66, pp. 160-168, 2014. 